\title{
THE PROFILE AND EXPERIENCES OF SERVICE PROVIDERS WITH REHABILITATION SERVICES IN THE WESTERN CAPE
}

\begin{abstract}
The 2010 South African health plan has highlighted the need to ensure a qualified workforce in order to improve access to quality health care. The aim of this study was to determine the profile of service providers involved in providing rehabilitation services to people with disabilities, and to explore their experiences using an explorative, qualitative framework. This study was conducted at three community health centres in the Western Cape. Participants were rehabilitation professionals. Data was collected by means of semi-structured interviews. The recorded interview was played back to the participants at the end of the interview. Transcripts were transcribed verbatim, and pre-determined themes were identified from the interviews. The understanding and experience of service providers with rehabilitation service were brought to light under four main themes. Accessibility within the centre was a challenge. Transport for persons with disabilities was a challenge because time schedules were not adhered to, and patients missed appointments. This was a challenge in structuring the sessions as there were long waiting periods. Resources and budget with regard to equipment were a challenge. Based on the findings of the study, there may be a need to reorganise rehabilitation services to improve accessibility to these services while maintaining service quality.

\section{Mlenzana, N (PhD) ${ }^{1}$ \\ Eide A (PhD) $)^{2}$ \\ Frantz J (PhD) $)^{3}$}

University of the Western Cape, Physiotherapy Department

SINTEF Technology and Society, Stellenbosch University

University of the Western Cape, Faculty of Community and Health Sciences
\end{abstract}

\section{KEY WORDS: PROFILE, EXPERIENCES, SERVICE PROVIDERS, REHABILITATION SERVICE}

\section{INTRODUCTION}

According to literature (Henderson and Tulloch 2008; Packenham-Walsh and Bukachi 2009), health care professionals play a crucial role in service provision, it is important to ensure that their knowledge, skills and attitudes are sound, in order to provide good quality service. According to Henderson and Tulloch (2008), the knowledge, attitude and beliefs of health service providers are important foundations for quality service delivery.

\section{Corresponding Author:}

N. Mlenzana

University of the Western Cape,

Physiotherapy Department

Email:nmlenzana@uwc.ac.za
It is recognised that qualified service providers are vital to the success of health systems, but are often neglected. According to Henderson and Tulloch (2008, p.2), various factors may contribute to the shortage of skilled service providers; these include "a lack of effective planning, limited health budgets, migration of health workers, inadequate numbers of students entering and/or completing professional training, limited employment opportunities, low salaries, poor working conditions, weak support and supervision, and limited opportunities for professional development". A study by Cockcroft et al. (2011) clearly highlights how the negative experiences of service providers can influence service delivery if not addressed.

In the health plan and national rehabilitation policy, this aspect of health professionals for rehabilitation is not being adequately addressed (Department of Health, 2000). The 2010 healthcare plan highlighted the need to ensure a qualified workforce in order to improve access to quality health care. According to the 2020 healthcare plan, focusing on a patient-centred approach to health care would enable health care professionals who are experienced to drive this approach. However, gaining insight into how health care providers perceive quality of care is important. In the Primary Health Care approach in the health system in South Africa, the rehabilitation process requires rehabilitation professionals to be available to ensure good service delivery and effective outcomes. The aim of this study was to determine the profile and explore the experiences of service providers who are providing rehabilitation services to people with disabilities. 


\section{METHODOLOGY}

\section{Research setting}

This study was conducted at three community Health Centres in the Western Cape Province. The three centres that were chosen had different rehabilitation team members and were based in urban and peri-urban areas. One of the centres had only two rehabilitation professionals based in the centre, compared to the other centres that had all the team members essential to providing rehabilitation service. Community Health Centres (CHCs) in South Africa deliver Primary Health Care services to the urban and peri-urban communities in their direct vicinity. Some therapists work alone, and provide both acute and rehabilitation services. This study was conducted at the three community health centres that provide preventative, promotive, curative and rehabilitative services for all patients, including people with physical disabilities.

\section{Research Design}

This study employed an explorative, qualitative framework. Information regarding the demographic profile of service providers was obtained from the participants through a questionnaire filled in at primary health care settings, and the qualitative data focused on the

Table 1: Themes and categories identified

\begin{tabular}{|c|c|}
\hline Themes & Categories \\
\hline Accessibility & $\begin{array}{l}\text { Transport } \\
\text { Communication } \\
\text { Human Resources } \\
\text { Catchment area } \\
\text { Environment } \\
\text { Equipment } \\
\end{array}$ \\
\hline Rehabilitation process & $\begin{array}{l}\text { Patient consent and goal setting } \\
\text { Family involvement } \\
\text { Information provision } \\
\text { Structure of rehabilitation sessions }\end{array}$ \\
\hline Resources & $\begin{array}{l}\text { Budget } \\
\text { Skills of service providers } \\
\text { Physical environment }\end{array}$ \\
\hline $\begin{array}{l}\text { Satisfaction with service } \\
\text { delivery }\end{array}$ & $\begin{array}{l}\text { Staff availability } \\
\text { Monitoring and evaluation } \\
\text { Workload } \\
\text { Equipment } \\
\text { Referral system } \\
\text { Budget } \\
\end{array}$ \\
\hline
\end{tabular}

perceptions of service delivery through semi-structured interviews.

\section{Population and sampling}

All willing service providers employed at the selected centres participated in the study. According to De Vos et al. (2005), "volunteer sampling" refers to a method of sampling in which the participants volunteer to participate in a research study. Silverman (2000), as cited in De Vos et al. (2005, p.330), states that the significant advantage of using volunteer sampling is that the respondents will provide accurate and relevant information for the study.

\section{Instrumentation}

Data was collected by means of semistructured interviews. The interviews lasted an average of 45-60 minutes. Following the completion of the sociodemographic information, the participants were then interviewed to further explore their experiences with rehabilitation services. An interview guide was developed based on pre-determined themes identified in the following documents: the National rehabilitation policy, community based rehabilitation matrix, and UNCRPD. The questions were developed focusing on the seven objectives of the NRP, aspects from the CBR

matrix, and five of the health and rehabilitation articles from the UNCRPD. During the interviews, the researcher continued to reflect on the comments made by the participants and highlighted the main concepts in order to ensure that the information obtained was correct.

\section{Procedure}

Permission to conduct the study was obtained by receiving ethics clearance from Senate Research Grants and Study Leave Committee, Department of Health in Western Cape Province, and facility managers of the three community health centres. Appointments for conducting semi-structured interviews were scheduled with service providers, and interviews were conducted by the researcher in English. All interviews were tape-recorded after gaining consent from the participants. After the interview, the tape was played back to the participants in order to ensure that the information gathered was recorded clearly. Transcripts were transcribed verbatim, and pre-determined themes were identified from the interviews, and sub-themes were identified to support the themes. The researcher identified an independent person to analyse the data for sub-themes in order to correlate the information gathered by the researcher. The interviews were analysed using Braun and Clarke's (2006) six-phase guide to conducting a thematic analysis. Thematic analysis is seen as a basic method for qualitative analysis and encompasses everything from identifying to analysing and reporting patterns within data. The researcher and the independent researcher met to check that the themes identified were similar.

\section{RESULTS AND DISCUSSION Socio-demographic information of service providers}

From the service providers, 16 volunteered to participate in the study, including occupational therapists, physiotherapists, facility managers, speech therapists, a clinical nurse practitioner, a doctor, a social worker and an orthopaedic sister. The mean age of the participants was 36.4 years with a range of 24 years to 58 years. Work experience among participants was an average of 
9.1 years with an average of 5.3 years' experience in the area of rehabilitation.

The understanding and the experience of service providers with rehabilitation service were grouped under four main themes: accessibility, rehabilitation process, resources, and satisfaction with service delivery. The main themes and categories are given in Table 1 below.

\section{ACCESSIBILITY}

\section{Environmental}

Participants addressed various aspects of accessibility. They first mentioned the accessibility of the institutions with regard to the building itself and access to the services provided. This was considered satisfactory, and providers mentioned the signage at the centres indicating the location of services for patients. Although this is available and in a language that is understandable to all the clients, some providers felt that the signs were placed too high on the walls for patients in wheelchairs to read, which is stressful to patients trying to find directions to different areas of the centres.

"There is signage... but signs are quite high and not all my patients can read" PT Centre G and B

"we have a complaints box and there are no complaints in there instead we get thank you notes" Volunteer Centre B and PT Centre G

When one is focusing on access, there are dimensions that need to be taken into consideration such as availability, geographic accessibility, affordability, and acceptability (Eldar 2004; O'Donnell 2007). Barriers to accessing health services can exist from the consumers' side and/or the providers' side (Ensor and Cooper 2004; (O'Donnell 2007). Hoenig et al. (1999) feel strongly that outcomes of rehabilitation can be influenced by organisational structure, hence it is important to make sure that patients are accommodated satisfactorily when they visit the health care centres.

\section{Human resources}

Even though there is satisfaction with rehabilitation service in the centres, service providers are dissatisfied with the shortage of rehabilitation professionals. This is a challenge, especially when there is a patient backlog for rehabilita- tion professionals. This backlog can also be associated with the big catchment areas that are covered by these centres. This is what was said about human resources:

"....We have a backlog of patients that stretches up to a month later, so if I am seeing patients now, he [a new patient] will only get an appointment in 2-3 weeks' time" PT Centre E

"...if they have chronic conditions they might be put on a waiting list and might be asked to attend the group sessions..." PT Centre B

Human resources need to be organised prior to service delivery. Gupta et al. (2011) insist that if human resources are not well organised there will be flaws in the delivery of service. In South Africa, delivery of rehabilitation services is still under strain. The rehabilitation policy was developed with the hope of improving provision of rehabilitation services (DoH 2000). Currently, service providers have found alternatives such as waiting lists and group sessions, but is this addressing the needs of the population?

\section{Transport}

Transport is a challenge that is often identified in literature (Kahonde et al. 2011). Service providers highlighted the limited service provision related to transport, and felt that this is an area that needs attention.

"We do not supply transport for patients. Dial-a-ride is available but patients have to wait very long to get the service". PT Centre G

"The only thing that is available is the Dial-a-ride... patients need to register with the organisation before they can get use of it." FM Centre B

Hoenig et al (1999) found that outcomes of patients who were admitted to hospital, compared with those who were receiving treatment by visiting the centre, were poor, because the patients were less motivated than those coming from home. Even though transport in this study is seen as a barrier for those patients who have appointments, they do benefit from the service received at the CHCs.

\section{Communication}

Service providers indicated that communication on the whole was adequate, but there were some challenges, especially those relating to language barriers. Lack of access to translators tends to be a frustration as it impacts on service provision.

"I have seen most of my Xhosa speaking people in this area, and the sister there speaks isiXhosa, so I have used her as a translator. It is frustrating, sometimes using the security guards" OT E

"Sometimes language is not understandable... language needs to be worked on". Volunteer Centre B

Participants expressed difficulty in imparting information to the patients during and after treatment because most patients spoke French and isiXhosa. Brez et al. (2009) identified clear communication of detail as a facilitator when dealing with patients. It is clear that the service providers found that if there is some way of communicating with patients, it is better than being totally unable to communicate with them.

\section{Accessible equipment}

Service providers identified the lack of suitable equipment for rehabilitation as a concern, and a basic example given is the height of plinths for patients with disability, as the beds are not adjustable. For effective service, adequate equipment should be a priority.

"I would like parallel bars as these are safer to walk weak patients than an assistive device". PT Centre G

"We have high beds we also need more plinths because our plinths are getting quite old". PT Centre B

Brez et al. (2009) noted that if patients have access to equipment to help monitor and manage their illness, there are good outcomes in the progress of the illness. If we are to move to a patientcentred approach to health care, then developing independence of patients during sessions is important, and a basic start is independent transfers that can be facilitated with adequate equipment.

\section{REHABILITATION PROCESS \\ Patient consent}

Health care professionals, when dealing with patients, are expected to obtain permission when assessing and treating patients. It is an important factor in building a relationship with patients, so that they can be open and free to disclose 
to the health care professional the cause of their visit to the health centre. When participants were asked if they obtain consent from the patients, they said the following:

"Basically at the beginning of my sessions, I ask patients that they become involved, we normally ask consent, and explain/inform that it will work, if they come back after every session." PT Centre E

"Before I start a treatment I inform the patient what I am going to do and make sure I have his or her consent to carry on with the treatment." PT Centre G

\section{Goal setting}

Linked to patient consent is goal setting. There was a clear drive among the health care professionals to include the patients in the area of goal setting.

"...it is essential that my patients get involved and participate in their rehabilitation. I ask the patients what his or her expectations are from the treatment. Once this is done, we plan the treatment together". PT Centre G

"I have patients that come here and they would cry, all I can do is encourage them, motivate them" Volunteer Centre B

Fuller et al. (2011) stress that if the management of the patient is goaldirected, it produces positive outcomes. This study proved that when involving patients in treatment, patients take ownership of their illnesses. This proves that if you involve patients and family members in treatment sessions, patients show involvement in the process.

\section{Family involvement}

The involvement of the family, for various reasons, during the rehabilitation process, is important; it is dependent on the type of disability, age of the patient, and language barriers,

"I do use a lot of the family support. I will do a lot of phone calls, for some children, I have done some creche visits..." OT Centre E

"I encourage families and caregivers to come in with my patients as it is important that they see what the patient is doing at their treatment sessions". PT Centre G

Family is one of the stakeholders in the rehabilitation process. It is seen as a support system for patients who are present- ing with disabilities. Fuller et al. (2011) discuss the concept of collaboration with other stakeholders to produce best clinical outcomes. In the present study, participants wanted to involve family members in the rehabilitation process.

\section{Information provision}

At the moment, the focus of rehabilitation is geared towards curative rather than health promotive rehabilitation, and when information is provided it is primarily focused on curative rehabilitation rather than health promotive rehabilitation. Health promotion is seen as a possible option and not a necessity in the rehabilitation process. Time to spend with the patients to share information was identified as a barrier to this study.

"we definitely provide the patients with all the information they need, even the exercises they need to do at home, we tell them exactly how to do it." Volunteer Centre B

Scheer et al. (2003) state that if a service provider does not have knowledge about the condition, it will be difficult to share information with the patients regarding their disabilities. Service providers in this study found it easier to give patients information.

\section{Structure of rehabilitation sessions}

A sequence of events have been drawn up that could negatively influence the rehabilitation sessions. These include: the long waiting periods for appointments, lack of adequate referral guidelines, length of treatment sessions, and content of care. All of these aspects play a role in caregiver training, which is an essential but much neglected aspect of rehabilitation.

"The waiting period of the referral system is long so yeah it does affect the rehab service delivery". PT Centre B,

"sisters are quite on top of things with the developmental disadvantages. They can say for instance they must be able to speak/say one word at 18 months, if not, they are referred to $m e$ ". PT Centre B

Scheer et al. (2003) strongly recommend that medical students and allied health students must be exposed to the proper processes of health care delivery for people with disabilities. The chal- lenges highlighted in the present study were linked to shortage of staff and increased workload among health care professionals.

\section{RESOURCES \\ Budget}

Budgets were highlighted as a major challenge. Budgets were linked to purchase of equipment as well as opportunities to train and improve knowledge amongst health care professionals.

"I feel like we really need training, we really need to get courses funded for". PT Centre B

"Basic seating course, was fantastic, and I am really thankful for that, even that was enough for me" OT Centre E

"I am still waiting for parallel bars and a wax bath. I must get round to ordering new hot packs which will be supplied". PT Centre G

Participants felt strongly that they should be taken for training as this would improve their level of knowledge and improve their skills. Brez et al. (2009) agree with the above statement as they say that lack of funding policies impacts on service delivery. In addition, inadequate budgets relating to purchasing of equipment affects service delivery.

\section{Skills of service providers}

Rehabilitation professionals have skills that they gained at the universities and institutions that they attended during their process of training to obtain their degrees. When they join institutions to work or to provide a service, they do what they learned, and develop themselves from there. However, it emerged that, although policies in the area of rehabilitation services do exist, there was a lack of awarerness about these policies.

"We write out guidelines down, like to write down the management of our patients". SOT Centre E

"I feel I am equipped to deal with any and all disabilities I encounter at the centre". PT Centre G

Skills of service providers need to be revived yearly. Even though some of the participants felt confident with their skills, they felt that they needed more skills to improve their treatment techniques for some of the conditions. Scheer 
et al. (2003) emphasise that service providers should be well trained to manage disabilities. They recommend that service providers should have knowledge about comprehensive health care needs of those presenting with disabilities.

\section{Physical environment}

Although there has been a shift from tertiary to primary health care, and service provision should take place at the primary health care level, all resources were not adjusted to primary level of care. This was emphasised by the lack of space available to provide services linked to rehabilitation. The service providers had the following to say about this matter:

"I would like more space to accommodate larger groups and parallel bars". PT Centre G

"The rooms are fine but we need more space...everyone fights for space". PT Centre B

Even though the participants were somehow comfortable with the space available, they were concerned when more people came and joined the team for a while. They felt that the room was overcrowded and inappropriate for team building because space was so limited. This is in line with the study that was conducted by Fuller et al. (b) (2011) who noticed that when services collaborate, some health professionals are satisfied with space and others are dissatisfied. The ones who were dissatisfied could not do their duties, owing to lack of space, but other participants were satisfied as they were visible to the patients. Physical environment needs to be userfriendly to all stakeholders to ensure good service.

\section{SATISFACTION WITH SERVICE DELIVERY \\ Staff availability}

Service providers feel that they are stretched to the limit in terms of numbers of staff. If there are staff absent, it further stretches the limited human resources available, and this definitely impacts on service delivery. Lack of posts for rehabilitation professionals is another definite challenge that is not in line with the primary health care approach.

"I would also like another physiother- apist to be appointed at Centre $G$ who would then cover the community work as there are so many physiotherapy referrals at the centre that I do not have time to go out into the community". PT Centre G and Centre B

Satisfaction is considered a health outcome and quality of care indicator, as well as a predictor of patient behaviour. It is perceived as a social construct between the consumers of health care, health care providers, and a component, as well as an outcome of effective care (Mahoney et al. 2004). Service providers in this study were dissatisfied with shortage of staff, and they felt strongly that there is a need for additional staff members to reduce their workload. This affects service delivery as service providers are overwhelmed by the workload.

\section{Monitoring and evaluation}

When providing a service, there must be systems in place to measure progress in what is being achieved. Some are dependent on patients' feedback and others on evaluation processes that are available within the centre. This is how the service providers are evaluated on what they are doing at the centres:

"My performance is assessed by my supervisor every quarter. She checks whether I have reached my targets for the quarter and also does a quality assurance audit". PT Centre G and B

"I think we also use the outcome measures of course not for all patients, we've got a couple in use especially for back, neck patients, we usually use it when they start till the end". PT Centre B

Monitoring and Implementation are factors that influence service delivery (World Health Organisation 2002; United Nations 2007) as they help to identify gaps in the service. In this study, service providers stated that monitoring and evaluation of their service were being carried out to check that they met their targets for the year.

\section{Workload}

Workload is a challenge in all the centres included in this study. Service providers felt that they did not have equal distribution of patients because there were long waiting lists, and a backlog of patients at some of the centres. The feeling was to get additional staff members to manage the workload at the centres. This is what they had to say about workload:

"CHC E has a backlog of patients that stretches up a month later, so if I am seeing a patient now, he will only get an appointment in 2-3 weeks' time". PT Centre E

"Inadequate staff, which might even be the problem why I might leave here that's how big it is. We really need community service PT because the workload is too much". PT Centre B

The above statements reflect dissatisfaction at being overwhelmed by the workload. This was a problem common to all the rehabilitation centres in this study. Some of the service providers wanted to leave the job because of dissatisfaction with the workload.

\section{Conclusion and implications for practice}

Based on the findings of the study, although rehabilitation professionals are passionate about their jobs, there is a need to have all the resources available to deliver a comprehensive service. They also expressed a need for continuous education in order to improve their skills through ongoing training, in order to update their knowledge about the profession. There may be a need to reorganise rehabilitation services to improve accessibility in all levels of rehabilitation services while maintaining service quality. This may indicate a new service delivery model that allows for more family interaction and patient interaction. Understanding and evaluating the multiple dimensions of quality in rehabilitation services are vitally important to generate useful knowledge to help clinical settings in their continuous efforts to improve quality. 


\section{REFERENCES}

Braun V, Clarke V 2006 Using thematic analysis in psychology. Qualitative Research in Psychology 3(2): 77-101

Brez S, Margo R, Malcolm J, Izzi S, Maranger J, Liddy C, Keely E, Ooi TK 2009 Transition from specialist to primary diabetes care: A qualitative study of perspectives of primary care physicians. BMC Family Practice 10:39

Cockcroft A, Milne D, Oelofsen M, Karim E, Anderson N 2011 Health services reform in Bangladesh: hearing the views of health workers and their professional bodies BMC Health Service Research 11(2): S8

Department of Health 2000. Rehabilitation for All. National Rehabilitation Policy. Pretoria South African Government Printers

De Vos AS, Strydom H, Fouche CB, Delport CSL 2005 Research at grass roots: for the social sciences and human service professions. Pretoria: Van Schaik Publishers

Eldar R 2004 Quality of Primary Care. Croatian Medical Journal 45(5): 679 - 684

Ensor T, Cooper S 2004 Overcoming barriers to health service access: influencing the demand side. Health Policy Planning, 19: 69-79

Fuller JD, Perkins D, Parker S, Holdsworth L, Kelly B, Roberts R, Martinez L, Fragar L 2011 Building effective service linkages in primary mental health care: A narrative review part 2. BMC Health Service Research 11:66

Fuller JD, Perkins D, Parker S, Holdsworth L, Kelly B, Roberts R, Martinez L, Fragar L 2011 Effectiveness of service linkages in primary mental health care: A narrative review part 1. BMC Health Service Research 11:72

Gupta N, Castillo-Laborda C, Landry M 2011 Health-related rehabilitation services: assessing the global supply of and need for human resources. BMC Health Services Research 11:276

Henderson LN, Tulloch J 2008 "Incentives for retaining and motivating health workers in Pacific and Asian countries". Human Resources for Health 6(18) UNDP
Hoenig H, Horner R, Duncan PW, Clipp E, Hamilton B 1999 New Horizons in stroke rehabilitation research. Journal of Rehabilitation Research and Development $36(1): 19-31$

Kahonde CK, Mlenzana N, Rhoda AJ 2010 Persons with physical disabilities' experiences of rehabilitation services at community health centres in Cape Town. South African Journal of Physiotherapy, 66(3): 2-7

Mahoney JK, Simon-Rusinowitz L, Loughlin MD, Desmond MS, Squillace RM 2004 Determining Personal Care Consumers' Preferences for a ConsumerDirected Cash and Counseling Option: Survey Results from Arkansas, Florida, New Jersey, and New York Elders and Adults with Physical Disabilities.Health Service Research 39(3): 643-664

O'Donnell O 2007 Access to health care in developing countries: breaking down demand side barriers. Cadernos de Sau'de Pu'blica 23: 2820-34

Pakenham-Walsh N, Bukachi F 2009 Information needs of health care workers in developing countries: a literature review with a focus on Africa. Human Resources for Health 7:30

Scheer J, Kroll T, Neri MT, Beatty P 2003 Access Barriers for Persons with Disabilities: The Consumer's Perspective. Journal of Disability Policy Studies 13: $221-230$

Silverman D 2000 Analysing talk and text. In NK Denzin, YS Lincoln (Eds.) Handbook of qualitative research 2 nd edn, pp821-834. London: Sage

United Nations 2007 Economic and Social Council. Monitoring of the implementation of Standard Rules on the Equalisation of Opportunities for Persons with Disabilities. 45th Session of the Commission for Social Development

World Health Organization 2002 The UN Standard Rules on the Equalisation of Opportunities for Person with Disabilities: NGO Responses to the Implementation of the Rules on Medical, Rehabilitation, Support Services and Personnel Training. WHO Geneva Switzerland

World Health Organization 2005 Disability and Rehabilitation WHO Action Plan 2006-2011 Geneva WHO http://www.who.int/disabilities/publications/ dar action plan 2006to2011.pdf 


\section{OMPTG presents OMT courses \\ in 2015 in the following provinces}

The OMT course runs over one year starting towards the end of January 2015 and ending with an open examination in October 2015. Successful completion of this course qualifies you to become an Advanced Professional Development Level 2 member of the OMPTG. It will be presented in SG (Johannesburg) and KZN (Durban)

The course strives to be evidence-based and covers the current approaches on joint, muscle and peripheral neural tissue treatment, as well as rehabilitation of movement control. The course is run over several modules and to qualify for a certificate a theoretical, practical and clinical examination, as well as a research assignment must be successfully completed.

Please contact the course leaders below for more information

South Gauteng

Merinda Rodseth merindarodseth@gmail.com
Kwa-Zulu Natal Rogier van Bever Donker rogier_vbd@yahoo.com

\section{AccountsdotCom offers!}

- charging to be hand collected, e-mailed or faxed

- billing and submitting via QEDI

- sending statements to patients via post, fax or e-mail

- sending weekly sms messages for member liable accounts

- taking legal steps for bad debt, without extra costs

- reconciliation with medical aid on accounts from 60 days

- full reconciliation report

- banking of cheques for the practice

- printing of all month-end documents

- printing of locum reports for easy payments

- hand delivering of all IOD / Polmed IOD accounts

- handling of all public enquiries

- reconciliation of medical payments with practitioners bank statements

- handling of all extra requests

\section{All of this for a set fee!}

If you're looking for extra special service where the practitioner as well as the patient's needs are handled with the utmost care ... AccountsdotCom is the solution!

Phone now 012 653-7200 or 012 653-7122 or fax 012 653-7850 or e-mail accountsdotcom@gmail.com

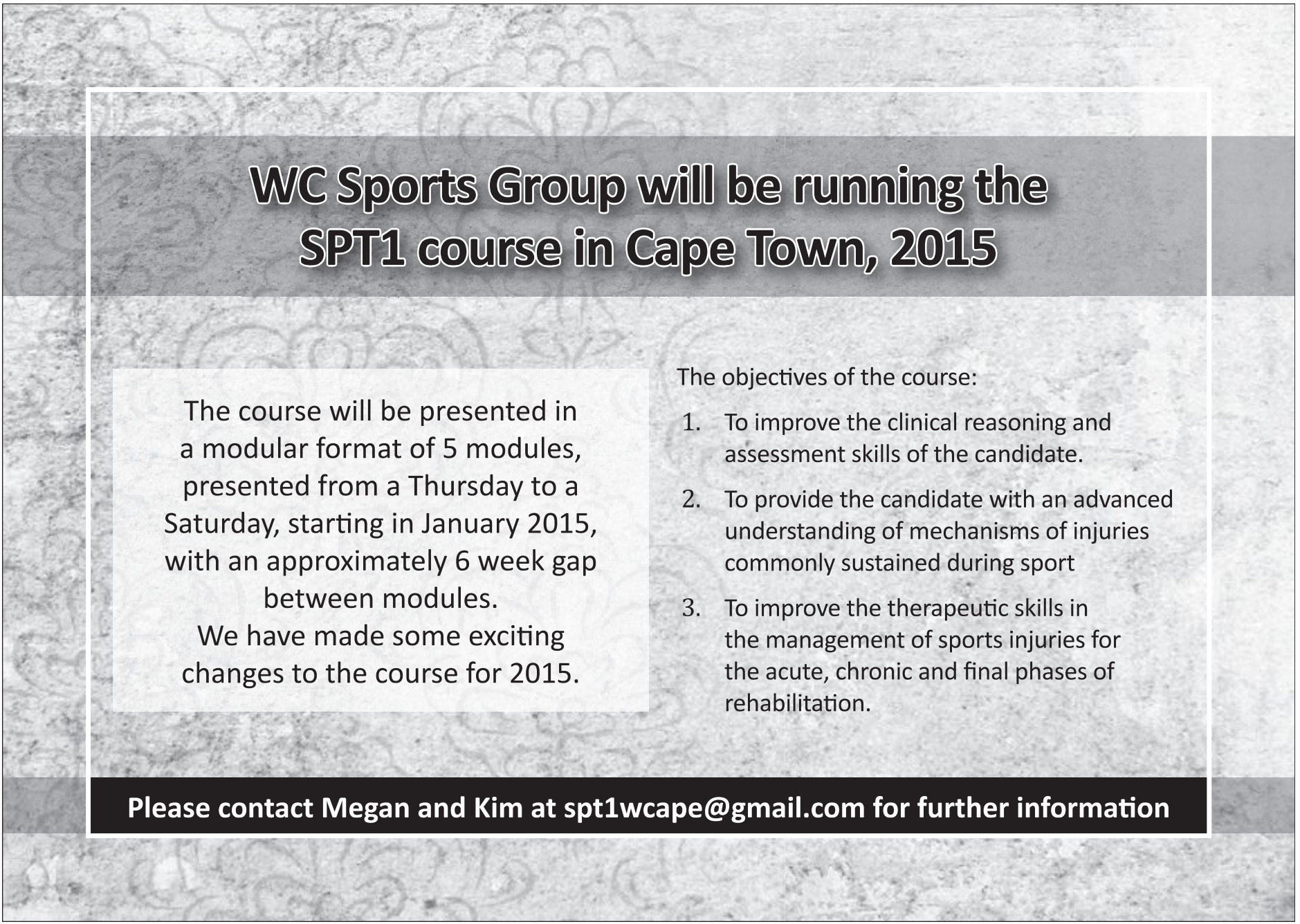

